\title{
Effects of Corticotropin-Releasing Factor on Brain Serotonergic Activity
}

\author{
Michelle L. Price, B.A., Andre L. Curtis, Ph.D., Lynn G. Kirby, Ph.D., Rita J. Valentino, Ph.D., \\ and Irwin Lucki, Ph.D.
}

The serotonergic dorsal raphe nucleus is innervated by corticotropin-releasing factor (CRF) and expresses CRF receptors, suggesting that endogenous CRF impacts on this system. The present study characterized interactions between CRF and the dorsal raphe serotonin (5-HT) system. The effects of intracerebroventricularly (i.c.v.) administered CRF on microdialysate concentrations of 5-HT in the lateral striatum of freely moving rats were determined. CRF had biphasic effects, with 0.1 and $0.3 \mu \mathrm{g}$ decreasing, and $3.0 \mu \mathrm{g}$ increasing 5-HT dialysate concentrations. I.C.V. administration of CRF inhibited neuronal activity of the majority of dorsal raphe neurons at both low (0.3 $\mu \mathrm{g})$ and high $(3 \mu \mathrm{g})$ doses. Likewise, intraraphe administration of CRF (0.3 and $1.0 \mathrm{ng})$ had predominantly inhibitory effects on discharge rate. Together, these results suggest that CRF is positioned to regulate the function of the dorsal raphe serotonergic system via actions within the cell body region. This regulation may play a role in stress-related psychiatric disorders in which 5-HT has been implicated.

[Neuropsychopharmacology 18:492-502, 1998] (C) 1998 American College of Neuropsychopharmacology. Published by Elsevier Science Inc.
KEY WORDS: Serotonin; Corticotropin-releasing factor; Dorsal raphe nucleus; Striatum; In vivo microdialysis; Indoleamine

Corticotropin-releasing factor (CRF) is the hypothalamic neurohormone that initiates the release of adrenocorticotropic hormone (ACTH) from the anterior pituitary during stress (Vale et al. 1981). In addition, CRF is thought to function as a brain neurotransmitter that interacts with other neurotransmitter systems to coordinate autonomic and behavioral components of the

From the Departments of Psychiatry and Pharmacology, Institute of Neurological Sciences, University of Pennsylvania (MLP, LGK, IL), Philadelphia, PA; and the Department of Psychiatry, Allegheny University of the Health Sciences (ALC, RJV), Philadelphia, PA.

Address correspondence to: Dr. Irwin Lucki, Departments of Psychiatry and Pharmacology, Institute of Neurological Sciences, University of Pennsylvania, 3600 Market St., Rm. 748, Philadelphia, PA 19104-2648.

Received July 22, 1997; revised November 5, 1997; accepted November 13, 1997. stress response (Dunn and Berridge 1990; Owens and Nemeroff 1991; Valentino et al. 1993). This is supported by anatomical studies that have identified a widespread distribution of CRF-immunoreactive neurons and fibers outside of the hypothalamic-pituitary axis in brain regions that are not directly involved with endocrine responses to stress (Sakanaka et al. 1987; Swanson et al. 1983). This distribution far exceeds that required for CRF-evoked release of ACTH. Consistent with this widespread distribution of CRF-immunoreactive terminals, CRF receptor binding sites and CRF receptor mRNA are localized in diverse brain regions that are unrelated to their pituitary actions (Chalmers et al. 1995; De Souza 1987; Potter et al. 1994).

Among the brain regions that are both innervated by CRF-immunoreactive fibers (Sakanaka et al. 1987; Swanson et al. 1983) and that contain mRNA for CRF receptors (Chalmers et al. 1995; Potter et al. 1994) are the dorsal and median raphe nuclei, the source nuclei of forebrain serotonergic innervation (Azmitia and Segal 1978; Kellar et al. 1977; Vertes 1991). Taken with evi- 
dence for an impact of stress on forebrain 5-HT (Chaouloff 1993; De Souza and Van Loon 1986; Dunn 1988; Kirby et al. 1997; Morgan et al. 1975; Pol et al. 1992; Tanaka et al. 1983), these anatomical findings lead to the speculation that CRF release within the raphe nucleus may mediate the effects of stress on this system.

Nonetheless, there are few reports of the effects of $\mathrm{CRF}$ on measures of 5-HT function, and these have yielded equivocal results. For example, relatively high doses of CRF failed to alter levels of the 5-HT precursor, 5-hydroxytryptophan (Van Loon et al. 1982). Similarly, tissue levels of 5-HT or its catabolite 5-hydroxyindoleacetic acid (5-HIAA) were unaltered by CRF (Dunn and Berridge 1987). In contrast, CRF increased activity of tryptophan hydroxylase, the rate-limiting enzyme in the synthesis of 5-HT, in cortex and midbrain (Singh et al. 1991), and 5-HIAA levels, measured by microdialysis, in hypothalamus and prefrontal cortex (Lavicky and Dunn 1993). Each of these studies used relatively indirect measures of 5-HT activity. A recent study, using in vivo microdialysis to measure extracellular 5-HT levels in the hippocampus of freely-moving rats, found no change after long term administration of CRF (Linthorst et al. 1997), and preliminary studies of this group suggested that acute CRF administration increased extracellular 5-HT in hippocampus (Reul and Linthorst 1997).

The present study used neurochemical and electrophysiological approaches to systematically characterize and quantify interactions between CRF and the dorsal raphe 5-HT system. In vivo microdialysis was used to measure extracellular levels of 5-HT in the striatum of freely-moving rats before and after intracerebroventricular (i.c.v.) administration of a wide range of doses of CRF. The striatum was chosen because its 5-HT innervation derives solely from the dorsal raphe nucleus (Azmitia and Segal 1978; Geyer et al. 1976; Vertes 1991). In addition, the effects of i.c.v. and locally administered CRF on neuronal activity of putative 5-HT neurons in the dorsal raphe nucleus were investigated, to determine whether the effects observed in the terminal region could be attributed to actions at the level of the cell body.

\section{METHODS}

\section{In Vivo Microdialysis Studies}

Subjects. Adult male Sprague-Dawley rats (250-300 g) (Charles River; Wilmington, MA) were initially housed, two per cage, on a 12-h light schedule in a temperature controlled $\left(22^{\circ} \mathrm{C}\right)$ colony room. Rats were given unrestricted access to standard rat chow and water. Care and use of animals were carried out in accordance with the National Institutes of Health Guide for the care and use of laboratory animals.
Surgery and Protocol. Rats were anesthetized with sodium pentobarbital ( $40 \mathrm{mg} / \mathrm{kg}$ intraperitoneally [i.p.]) and positioned in a stereotaxic instrument. Holes were drilled for placement of 3 skull screws, a 22 gauge guide cannula (Plastics One, Roanoke, VA) above the lateral ventricle ( $-1.0 \mathrm{AP}, 1.5 \mathrm{ML}$, and $4.5 \mathrm{~mm}$ ventral to skull surface) and a 20 gauge guide cannula into the lateral striatum (- $0.3 \mathrm{AP}, 3.5 \mathrm{ML}$, and $3.2 \mathrm{~mm}$ ventral to brain surface). The cannulae were affixed to the skull with cranioplastic cement and the incision was closed with wound clips.

Following surgery, rats were individually housed. Rats were handled at least four times prior to microdialysis experiments which were conducted at least one week after surgery. On the day before the experiment a rat was placed into a clear polycarbonate cylindrical microdialysis apparatus ( $37.5 \mathrm{~cm}$ high) with a counterbalance arm attached to a liquid swivel and spring tether to allow free movement (Instech Laboratories, Plymouth Meeting, PA). A dialysis probe was inserted into the guide cannula in the lateral striatum. Custom concentric-style dialysis probes were constructed as previously described (Kirby and Lucki 1997) and continuously perfused with filtered artificial cerebrospinal fluid (ACSF) (147 mM NaCl, $1.7 \mathrm{mM} \mathrm{CaCl}, 0.9 \mathrm{mM}$ $\mathrm{MgCl}_{2}$, and $4 \mathrm{mM} \mathrm{KCl}, \mathrm{pH}$ 6.3-6.5) at a rate of $0.8 \mu \mathrm{l} /$ min using a Harvard Apparatus syringe pump (South Natick, MA or Instech Laboratories) through tubing inserted through the liquid swivel. Dialysate samples were collected 17-20 $\mathrm{h}$ after probe insertion at 20-min intervals for 2 hours prior to injections.

Either CRF (0.01-3.0 $\mu \mathrm{g}$ in 1 or $3 \mu \mathrm{l}$ saline) or saline ( 1 or $3 \mu \mathrm{l}$ ) was injected i.c.v. over a 30 -second period. Samples were collected at 10-min intervals for $40 \mathrm{~min}$ and then at 20-min intervals for the remaining 3.3 hours of the experiment. Samples were collected into polypropylene microcentrifuge vials (Fisher Scientific, Pittsburgh, PA) and stored at $-70^{\circ} \mathrm{C}$ until analysis. At the end of the experiment 1-3 $\mu$ l of green food coloring was injected through the i.c.v. cannula and rats were administered a lethal dose of pentobarbital $(100 \mathrm{mg} / \mathrm{kg}$, i.p.). Brains were removed, frozen in isopentane and stored at $-20^{\circ} \mathrm{C}$ until sectioned (see below). Only one dose of CRF or saline was administered to an individual rat.

Analysis of Dialysate Samples. Samples were automatically injected into a Bioanalytical Systems 460 High-Pressure Liquid Chromatograph (HPLC) (BAS, West Lafayette, IN) by a CMA/200 Refrigerated Microsampler (CMA, Stockholm, Sweden) set to a $6.5 \mu \mathrm{l}$ injection volume. The HPLC mobile phase $(0.67 \mathrm{mM}$ ethylenediaminetetraacetic acid, $0.43 \mathrm{mM}$ sodium octyl sulfate, $32 \mathrm{mM} \mathrm{NaH} \mathrm{PO}_{4}$, and $11-13 \%$ acetonitrile, $\mathrm{pH}$ 4.0) was pumped through a reverse phase $1 \times 100 \mathrm{~mm}$ ODS $3 \mu \mathrm{m}$ microbore column (C18; BAS) at a flow rate of $90 \mu \mathrm{l} / \mathrm{min}$ (see Kreiss et al. 1993). 
5-HT and 5-HIAA from chromatographs of dialysate samples were identified by comparing their elution times with those of reference standards. The amount of 5-HT and 5-HIAA in each dialysate sample was quantified from their respective peak heights using a linear regression analysis of the peak heights obtained from a series of reference standards. The detection limit, defined as the sample amount producing a peak height twice the height of background noise, was 0.5 fmoles, which is sufficient to measure levels of 5-HT with 10min resolution without the addition of a 5-HT reuptake inhibitor to the perfusion medium.

Data Analysis. Baseline levels of 5-HT and 5-HIAA were corrected for individual probe recoveries. Probe recovery was determined in vitro at room temperature with a standard solution of ACSF containing 5-HT (10 $\mathrm{mM})$ and 5-HIAA (150 mM). Probe recovery for 5-HT and 5-HIAA ranged between $18 \%$ and $35 \%$. Baseline levels were determined for each rat from the mean of dialysate samples collected before i.c.v. injection. The 5-HT and 5-HIAA content of individual dialysate samples was expressed as a percentage change from this baseline. Mean basal 5-HT and 5-HIAA values were compared between groups by one-way analysis of variance (ANOVA). The overall effect of treatment on 5-HT and 5-HIAA levels was assessed by one-way ANOVA. Comparisons between saline and CRF doses were made using ANOVA followed by Dunnett's test, as were the values at individual time points compared to baseline. Summed effects of treatment over the course of an experiment were measured by determining the area under the curve (AUC). AUC values were examined using ANOVA followed by Dunnett's test for comparisons between experimental and control groups.

Histological Analysis. Brains were sectioned with a refrigerated cryostat and mounted on gelatinized slides. The sections were stained with Cresyl Violet, cleared in a series of alcohol and xylenes and coverslipped. The brain was cut for visualization of the food coloring in the ventricular system. Sections were examined for localization of the dialysis probe tract and the i.c.v. cannula tract. Only rats with accurate placement of both the i.c.v. cannula and $100 \%$ of the dialysis probe membrane were used in data analysis.

\section{Electrophysiological Studies}

Subjects and Surgery. Male Sprague-Dawley rats (Taconic Farms; approximately 300 g) were anesthetized with a $1-1.5 \%$ halothane-in-air mixture administered through a nose cone and positioned in a stereotaxic instrument using blunt ear bars with the head in the horizontal plane. Body temperature was maintained at $37-38^{\circ} \mathrm{C}$ with a small heating pad. The skull was exposed and a hole, centered on the midline at $7.8 \mathrm{~mm}$ caudal to bregma was drilled, exposing the dura and associated superficial transverse and sagittal sinuses. The sagittal sinus and dura were ligated, transected and reflected to allow for a midline approach towards the dorsal raphe nucleus with minimal blood loss. For experiments which required i.c.v. administration of CRF, a hole was drilled $1.0 \mathrm{~mm}$ caudal to bregma and $1.5 \mathrm{~mm}$ lateral to midline for placement of a 26 gauge stainless steel cannula into the lateral ventricle, $5.6 \mathrm{~mm}$ ventral to skull surface.

Recording and CRF Administration. For studies of the effects of i.c.v. administered CRF, neuronal activity was recorded from single barrel glass micropipettes (2-4 $\mu \mathrm{m}$ diameter, 4-7 MOhm) filled with $2 \%$ Pontamine Sky Blue (PBS) dye in $0.5 \mathrm{M}$ sodium acetate. Double barrel micropipettes were used to record single unit dorsal raphe neuronal discharge and simultaneously microinfuse CRF. This technique has been previously characterized and described in detail (Akaoka et al. 1992). Double barrel micropipettes consisted of a recording pipette (as described above) glued using a photopolymerizing resin (Silux, 3M Dental Products, St. Paul, MN) next to an infusion pipette (Fisher Scientific, Pittsburgh, PA). The infusion pipette (20-50 $\mu \mathrm{m}$ diameter tip) was angled at approximately $30-45^{\circ}$ with its tip adjacent to the tip of the recording pipette but $100 \mu \mathrm{m}$ dorsal. This was filled with a solution of CRF (0.01-0.03 $\mathrm{mg} / \mathrm{ml}$ ) and connected by PE tubing to a source of solenoid-activated pneumatic pressure (Picospritzer, General Valve, Inc., Fairfield, NJ). This infusion pipette was calibrated such that known volumes could be administered $(1 \mathrm{~mm}$ displacement $=60 \mathrm{nl})$.

The micropipette was advanced toward the dorsal raphe nucleus with a micromanipulator. Microelectrode signals were led from a preamplifier to filters and additional amplifiers. Impulse activity was monitored with an oscilloscope and loudspeaker to aid in localizing the dorsal raphe nucleus. Dorsal raphe neurons were tentatively identified during recording by their relatively slow and very regular spontaneous discharge rate $(0.5-2.0 \mathrm{~Hz})$, biphasic wave forms of $2-3 \mathrm{msec}$ duration (in unfiltered trace), and location at $5.0-5.5 \mathrm{~mm}$ below brain surface on the midline. When a stable, unitary action potential was isolated, an amplitude trigger was used to convert the occurrence of each action potential into a digital pulse.

Dorsal raphe spontaneous discharge rate was recorded for at least $10 \mathrm{~min}$ prior to CRF administration. CRF ( 0.3 or $3.0 \mu \mathrm{g}$ in $3 \mu \mathrm{l}$ ) was injected i.c.v. over a period of $30 \mathrm{sec}$. Intraraphe microinfusions were made by applying small pulses of pressure (10-30 psi, 20-40 ms duration) to the calibrated infusion pipette at a frequency of $0.1-0.5 \mathrm{~Hz}$ to deliver a volume of $30 \mathrm{nl}$. The movement of solution through the calibrated pipette was observed through a microscope throughout the in- 
Table 1. Baseline dialysate content

\begin{tabular}{lcccccc}
\hline & Saline & $\mathbf{0 . 0 1} \boldsymbol{\mu g}$ CRF & $\mathbf{0 . 1} \boldsymbol{\mu g}$ CRF & $\mathbf{0 . 3} \boldsymbol{\mu g}$ CRF & $\mathbf{1} \boldsymbol{\mu g}$ CRF & 3 $\boldsymbol{\mu g}$ CRF \\
\hline 5-HT & $4.4 \pm 1.0$ & $4.2 \pm 0.74$ & $3.8 \pm 0.65$ & $6.2 \pm 0.81$ & $5.0 \pm 1.7$ & $5.9 \pm 1.4$ \\
5-HIAA & $5.4 \pm 1.4$ & $5.8 \pm 0.64$ & $5.2 \pm 0.83$ & $6.9 \pm 1.2$ & $3.8 \pm 0.60$ & $5.2 \pm 1.1$ \\
& $(\mathrm{~N}=10)$ & $(\mathrm{N}=7)$ & $(\mathrm{N}=8)$ & $(\mathrm{N}=7)$ & $(\mathrm{N}=6)$ & $(\mathrm{N}=7)$ \\
\hline
\end{tabular}

Mean values ( \pm 1 SEM) for baseline striatal dialysate content of 5 -HT (fmol/ $6.5 \mu l$ sample) and 5-HIAA (pmol/6.5 $\mu \mathrm{l}$ sample) in different groups injected with either CRF or saline. The number of animals in each group is given in parenthesis. There were no significant differences between groups.

fusion. Injection of the entire volume at this rate usually required 60-90 sec. Neuronal activity was recorded for a period of $15-40 \mathrm{~min}$ after CRF administration. Only one dose of CRF was administered to an individual rat. At the end of the experiment, 8-hydroxy-2 (di- $n$-propylamino) tetralin (8-OH-DPAT; $0.025 \mathrm{mg} / \mathrm{kg}$, s.c.) was administered and discharge recorded for an additional $5 \mathrm{~min}$.

Histology. The recording site was marked by iontophoresis of PSB from the recording pipette $(-15 \mathrm{~mA}$, $10 \mathrm{~min})$. In experiments in which CRF was administered i.c.v., $5 \mu$ l of neutral red dye was injected through the i.c.v. cannula. Rats were injected with pentobarbital $(100 \mathrm{mg} / \mathrm{kg})$ and perfused transcardially with a $10 \%$ solution of paraformaldehyde. The brains were first cut to visualize i.c.v. administered neutral red and then stored in the fixative. Frozen $40 \mu \mathrm{m}$ sections were cut and mounted on glass gelatinized slides and stained with neutral red for visualization of the PSB spot (see Figure $3 \mathrm{~A}$, for example). The locations of recording sites were reproduced on plates 44, 45, and 46 of Brain Maps (Swanson 1992). Only data from recordings within the dorsal raphe nucleus were used in the analysis. In all experiments using i.c.v. administration neutral red was apparent in the ventricular system.

Data Analysis. Dorsal raphe neuronal discharge was recorded on-line on either an Apple 2E computer or Cambridge Electronics Design 1401 data analysis system using Spike-2 software. The mean discharge rate determined over at least ten 1-min intervals prior to CRF administration was taken as the mean basal discharge rate with subsequent rates expressed as a percentage of this mean. A repeated measures analysis of variance (ANOVA) was performed using this mean basal discharge rate to determine the significance of changes in post drug discharge rate.

Drugs. CRF was generously supplied by Dr. Jean Rivier of the Clayton Foundation Laboratories for Peptide Biology, The Salk Institute, La Jolla, CA. The peptide was dissolved in water to make a $1 \mathrm{mg} / \mathrm{ml}$ solution. Aliquots $(10 \mu \mathrm{l})$ of this solution were concentrated using a Savant Speed Vac concentrator. The $10 \mu \mathrm{g}$ aliquots were stored at $-70^{\circ} \mathrm{C}$ and dissolved in saline (for dialysis ex- periments) or ACSF (for electrophysiological experiments) on the day of the experiment.

\section{RESULTS}

\section{Effects of CRF on Extracellular 5-HT and 5-HIAA}

The mean basal dialysate concentration of 5-HT in the lateral striatum across all treatment groups was $4.9 \pm$ $0.4 \mathrm{fmol} / 6.5 \mu \mathrm{l}$ sample $(\mathrm{n}=44)$. This concentration is comparable to those determined in our previous studies (Kirby et al. 1997; Kirby and Lucki 1997). Table 1 shows the baseline dialysate concentrations of 5-HT from the lateral striatum for each experimental group. There were no significant differences in basal concentrations between treatment groups $(F(5,44)=0.79)$. The mean basal dialysate concentration of 5-HIAA across all treatment groups was $5.3 \pm 1.9 \mathrm{pmol} / 6.5 \mu \mathrm{l}$ sample. There were no significant differences in basal 5 -HIAA concentrations between treatment groups $(F(5$, $44)=0.62)($ See Table 1$)$.

CRF (0.01-3.0 $\mu$ g, i.c.v.) had biphasic effects on dialysate concentrations of 5-HT that were of a relatively long duration (Figure 1A, B). An overall two-way ANOVA indicated significant effects of dose $(F(5,546)=7.85$, $p<.001)$ and time $(F(14,546)=2.14, p<.01)$, but no significant interaction $(F(70,546)=1.48)$. As shown in Figure 1A, relatively low doses of CRF (0.1 and $0.3 \mu \mathrm{g})$ decreased dialysate concentrations of 5-HT in striatum compared to saline pretreatment; $(F(5,44)=2.88, p<$ $.05)$ and $(F(5,44)=2.78, p<.05)$ for 0.1 and $0.3 \mu \mathrm{g} C R F$, respectively. Dialysate concentrations of 5-HT were significantly reduced from $80-200 \mathrm{~min}$ after injection of 0.1 $\mu \mathrm{g}$ CRF to a maximum $58 \pm 14 \%$ reduction at $200 \mathrm{~min}$. Following $0.3 \mu \mathrm{g} \mathrm{CRF}, 5-\mathrm{HT}$ dialysate concentrations were significantly decreased from $40-140 \mathrm{~min}$ to a maximum $60 \pm 13 \%$ decrease at $40 \mathrm{~min}$ after injection. Neither saline, 0.01 or $1.0 \mu \mathrm{g}$ CRF altered dialysate concentrations of 5-HT in striatum (Figure 1A, B).

In contrast to lower doses, $3.0 \mu \mathrm{g}$ CRF significantly increased dialysate concentrations of 5-HT in striatum compared to saline injection $(F(5,44)=2.95, p<.05)$. This increase began almost immediately following injection and peaked at $79 \pm 42 \%$ above baseline values at 30 min after injection (Figure 1B). 5-HT concentrations 

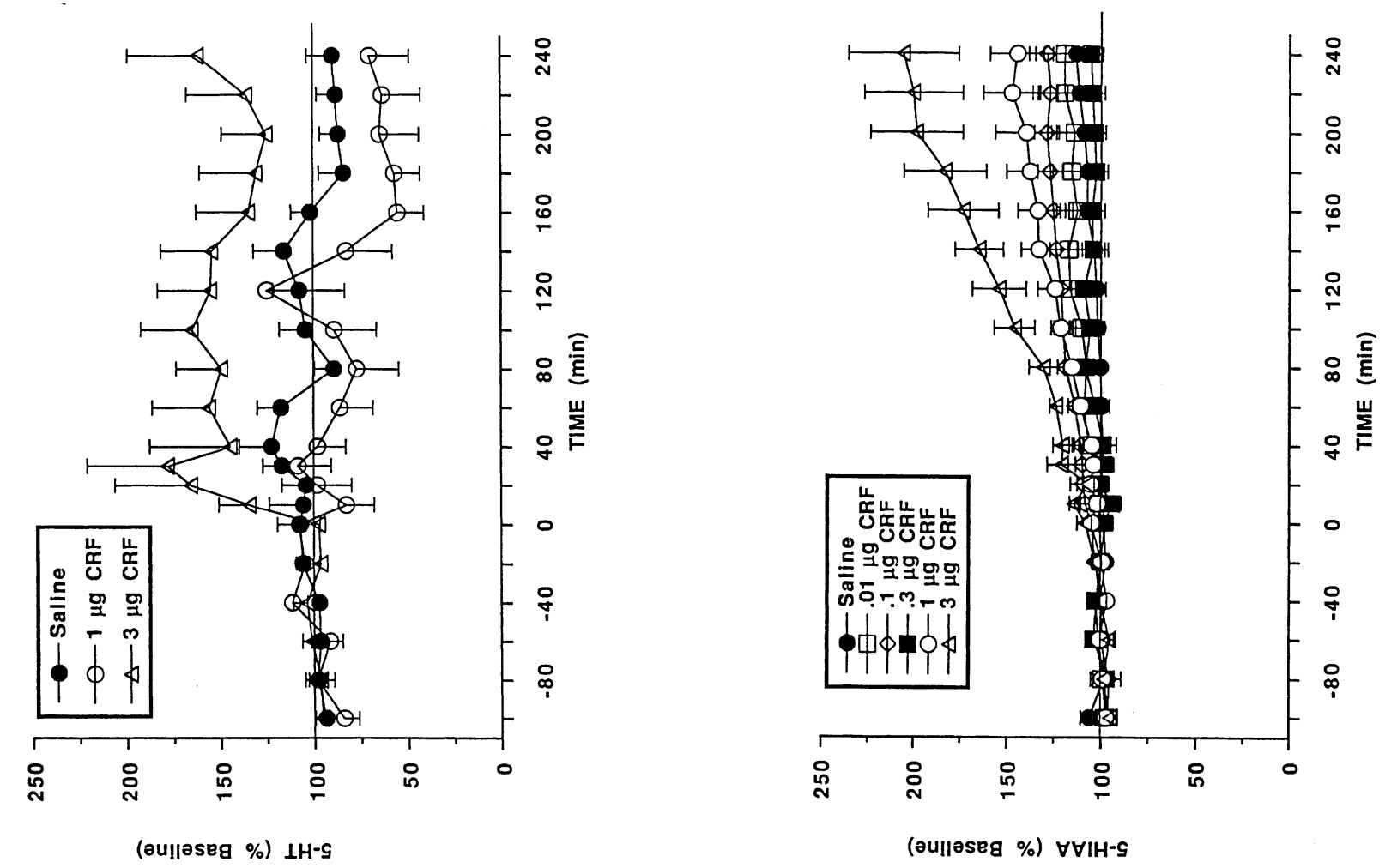

$m$
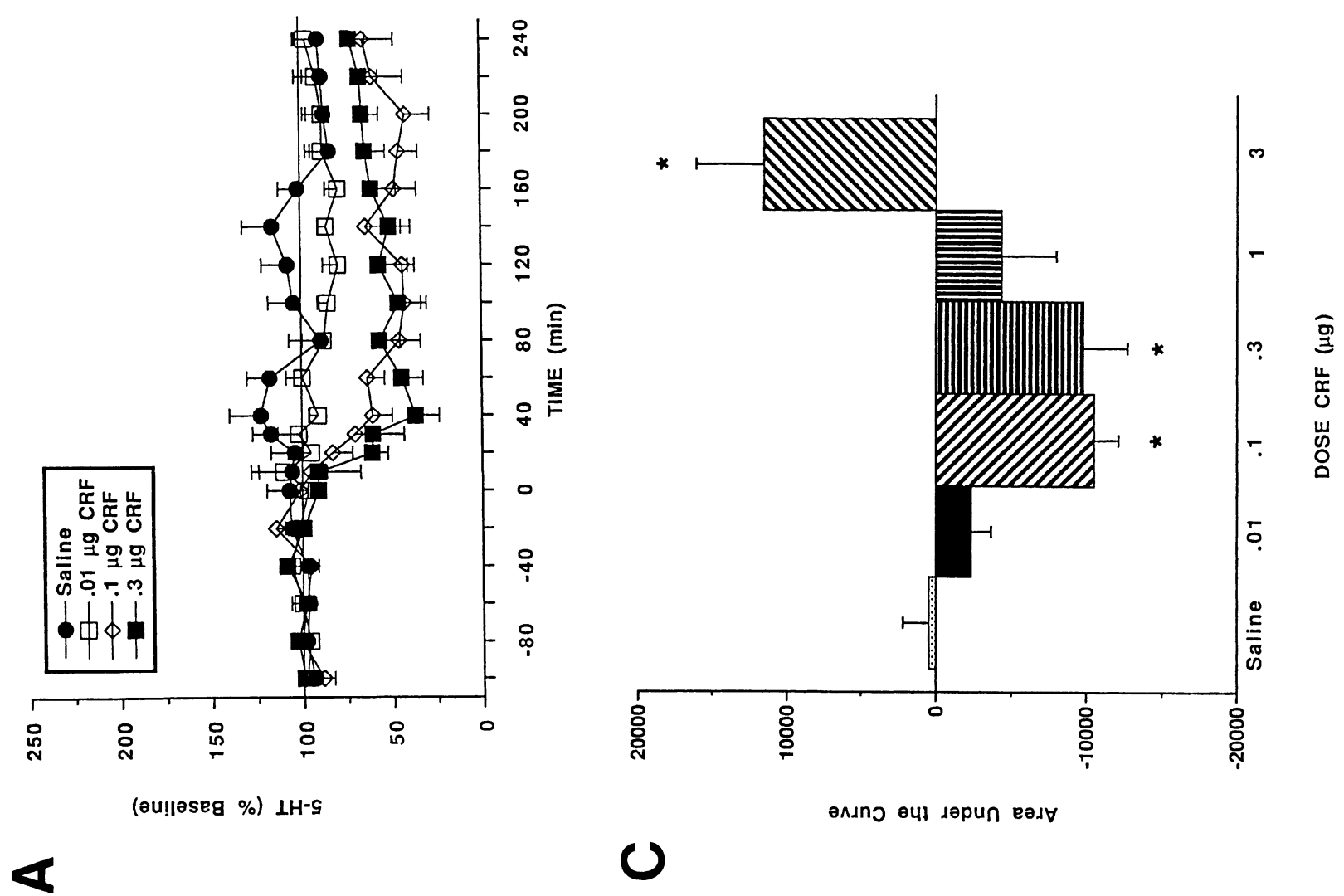

0 
remained elevated by at least $30 \%$ for the $240 \mathrm{~min}$ duration of the experiment. This dose of CRF resulted in grooming, burrowing and head shakes as previously reported (Ehlers et al. 1986). These behaviors were also observed with 0.1 and $0.3 \mu \mathrm{g} \mathrm{CRF}$, although they were less intense at these lower doses. In contrast, salineinjected rats often slept or were in a state of quiet waking throughout the experiment.

Figure 1C compares the effects of various doses of CRF on extracellular 5-HT using AUC values to summarize the overall effects of the individual doses $(F(5$, $44)=8.55, p<.001)$. AUC values were reduced significantly by 0.1 and $0.3 \mu \mathrm{g}$ CRF and increased by $3.0 \mu \mathrm{g}$ $\mathrm{CRF}$, compared to saline.

Figure 1D shows the effects of i.c.v. injection of CRF on dialysate concentrations of 5-HIAA in the lateral striatum. An overall two-way ANOVA revealed significant effects of dose $(F(5,546)=4.6, p<.01)$, time $(F(14$, $546)=22.6, p<.0001)$ and interaction $(F(70,546)=3.41$, $p<.0001)$. Only the $3 \mu \mathrm{g}$ dose of CRF produced a significant increase in dialysate 5-HIAA concentrations as compared to saline $(F(5,44)=4.5, p<.01)$.

\section{Effects of CRF on Dorsal Raphe Neuronal Discharge}

Discharge activity of dorsal raphe neurons was highly regular with frequencies ranging between 0.3 and 2.2 $\mathrm{Hz}$ and a mean frequency of $1.2 \pm 0.1 \mathrm{~Hz}(\mathrm{n}=35)$, comparable to previous reports (Aghajanian et al. 1968, 1970). Neurons were further classified with respect to their location within the dorsal raphe nucleus as being in the dorsomedial division (22 cells) or ventromedial division (13 cells). The mean discharge rate of neurons in these regions were not significantly different; $1.3 \pm$ $0.1 \mathrm{~Hz}$ and $1.0 \pm 0.2 \mathrm{~Hz}$, respectively. No neurons were recorded in the lateral wings of the nucleus.

Administration of $0.3 \mu \mathrm{g}$ CRF (i.c.v.), a dose that decreased extracellular 5-HT, had predominantly inhibitory effects on dorsal raphe neuronal discharge. Discharge rates of 12 of 15 neurons were decreased by $33 \pm$ $9 \%$ and the timecourse of this decrease was similar to that for effects on striatal 5-HT (Figure 2A). CRF increased discharge rates of the 3 remaining neurons by $99 \pm 24 \%$. Administration of a higher dose of CRF $(3$ $\mu g$, i.c.v.) that was associated with increased dialysate concentrations on 5-HT also had predominantly inhibi- tory effects on 5-HT neuronal activity. Of 10 neurons examined, CRF increased the discharge rate of 2 (by approximately $40 \%$ ) and decreased the discharge rate of the remaining eight neurons. The mean maximal inhibition determined in the eight neurons was $31 \pm 9 \%$. There were no statistically significant differences in the mean basal discharge rates of neurons that were inhibited versus neurons that were activated by CRF.

Like i.c.v. administration, microinfusion of CRF into the dorsal raphe nucleus had predominantly inhibitory effects on neuronal discharge. Figure 2B illustrates the inhibition produced by $0.3 \mathrm{ng} C \mathrm{CRF}$, which was typically of rapid onset. The lowest dose tested $(0.3 \mathrm{ng})$ inhibited each of 4 neurons, resulting in a mean decrease in the discharge rate of $27 \pm 3 \%$. A higher dose of CRF (1.0 ng) decreased discharge rates of 4 of 6 neurons and increased activity of the remaining 2 neurons. The mean frequency of all 10 neurons prior to CRF microinfusion was $1.1 \pm 0.2 \mathrm{~Hz}$ and all neurons were inhibited by systemic administration of 8-OH-DPAT.

Figure 3 shows the location of recording sites within the dorsal raphe nucleus. There was no apparent topographical organization of neurons with qualitatively different responses to CRF; i.e., neurons that were inhibited or activated by CRF were located at different rostro-caudal levels and in both the dorsomedial and ventromedial divisions of the nucleus.

\section{DISCUSSION}

The present study demonstrated biphasic effects of i.c.v. administered CRF on extracellular 5-HT in the striatum of unanesthetized rats, with lower doses decreasing, and higher doses increasing, extracellular 5-HT. The electrophysiological findings suggested that the inhibitory effects of CRF were the result of actions at the level of the cell body region. Thus, i.c.v. administered $\mathrm{CRF}$, in a dose that decreased extracellular 5-HT, also inhibited a majority of putative 5-HT dorsal raphe neurons and intraraphe microinfusion of much lower doses of CRF had predominantly inhibitory effects on neuronal discharge. Taken with reports of CRF innervation of the dorsal raphe (Sakanaka et al. 1987; Swanson et al. 1983) and the relatively high expression of CRF receptors in this nucleus (Chalmers et al. 1995; Potter et al.

Figure 1. Effects of CRF on striatal 5-HT and 5-HIAA. (A and B) The abscissae indicate time before and after i.c.v. injection, which occurred at time $=0$. The ordinates indicate extracellular 5-HT level/sample expressed as a percentage of the mean pre-injection level. A shows the effects of saline and CRF (0.01-0.3 $\mu$ g) and B shows the effects of saline and CRF (1.0-3.0 $\mu$ g). Each point represents the mean of 6-10 rats and vertical lines represent \pm 1 S.E.M. (C) The bars indicate the mean effect of saline or different doses of CRF on striatal 5-HT levels expressed as the area under the curve described by time and effect. Asterisks indicate that bars differed from saline, $p<.05$. (D) The abscissa indicates time before and after i.c.v. injection of saline or CRF $(0.01-3.0 \mu \mathrm{g})$. The ordinate indicates 5-HIAA striatal levels expressed as a percentage of the mean pre-injection level. Vertical lines represent \pm 1 S.E.M. 

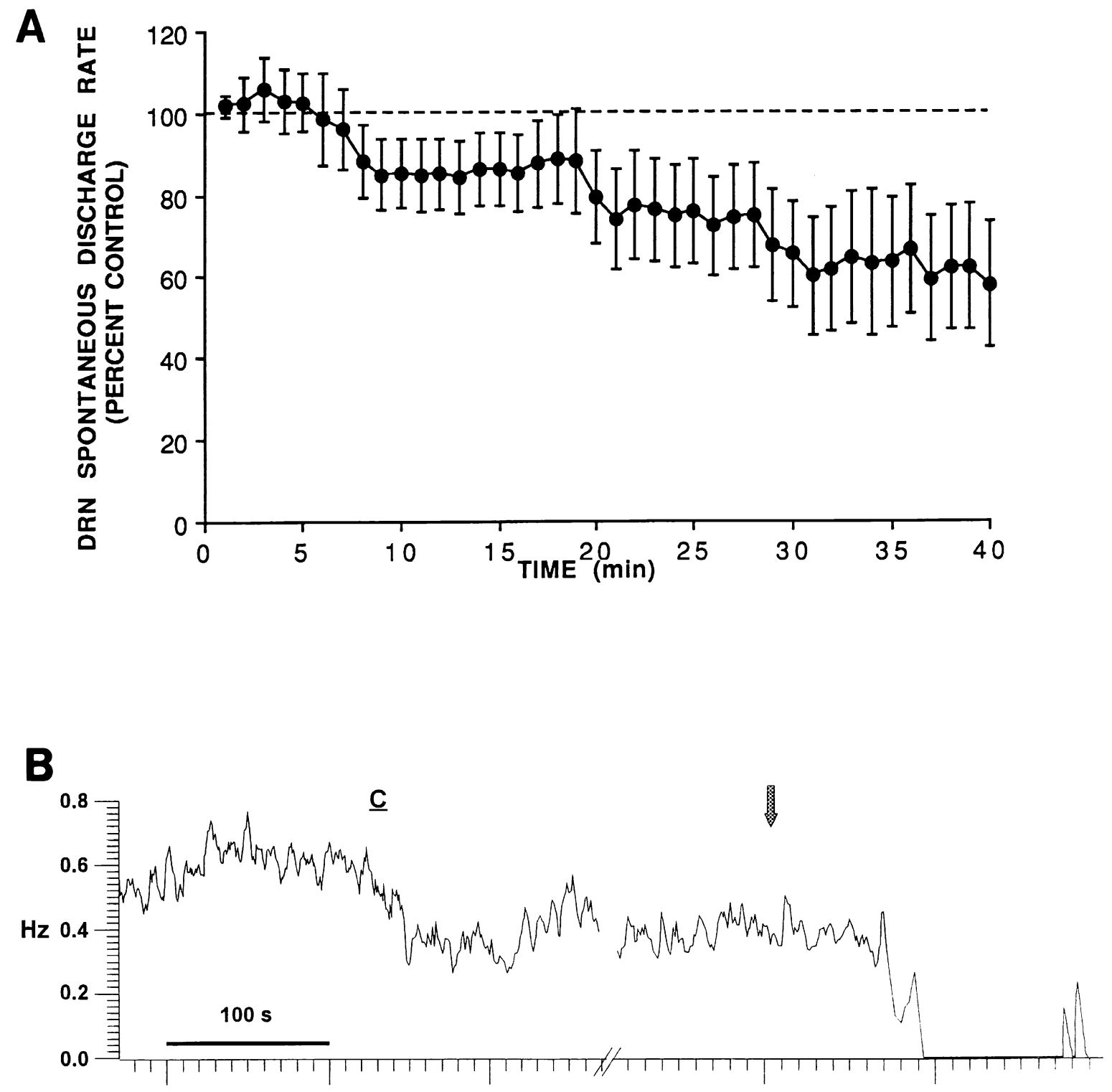

Figure 2. Effects of CRF on discharge rates of putative 5-HT dorsal raphe neurons. A) The abscissa indicates the time after administration of CRF $(0.3 \mu$ g, i.c.v.). The ordinate indicates discharge rate expressed as a percentage of the mean rate determined over the $10 \mathrm{~min}$ prior to injection. Points represent the mean of 12 neurons that were inhibited by CRF (note: 3 other neurons that were activated by CRF were not included in this analysis). Vertical lines represent \pm 1 S.E.M. B) Record of mean frequency of a single dorsal raphe neuron. The abscissa indicates time (calibration bar $=100 \mathrm{~s}$ ) and the ordinate indicates discharge rate $(\mathrm{Hz})$. CRF $(0.3 \mathrm{ng}$ in $30 \mathrm{nl})$ was microinfused at the bar below "C." The break in the record represents the time between saving one file and starting another (approximately $30 \mathrm{~s}) .8-\mathrm{OH}$-DPAT $(0.025 \mathrm{mg} / \mathrm{kg}$, s.c.) was administered at the arrow and completely inhibited neuronal discharge and this gradually recovered.

1994), these findings suggest that endogenous CRF may regulate activity of the dorsal raphe 5-HT system. This regulation may play a role in certain psychiatric disorders in which both 5-HT and CRF have been implicated.

This is the first full report describing an acute effect of CRF on extracellular 5-HT levels and on neuronal activity of putative 5-HT dorsal raphe neurons. The relatively slow onset of effect after i.c.v. administration may be attributed to diffusion of the peptide from the third ventricle into the dorsal raphe nucleus, which extends hundreds of microns below the ventricular surface. Both the slow onset and long duration of CRF are consistent with other reports of the effects of i.c.v. administered CRF (Ehlers et al. 1986; Liang et al. 1992).

The biphasic nature of CRF effects on extracellular 5-HT, and particularly the inhibitory effects, would not be predicted on the basis of previous reports that dem- 


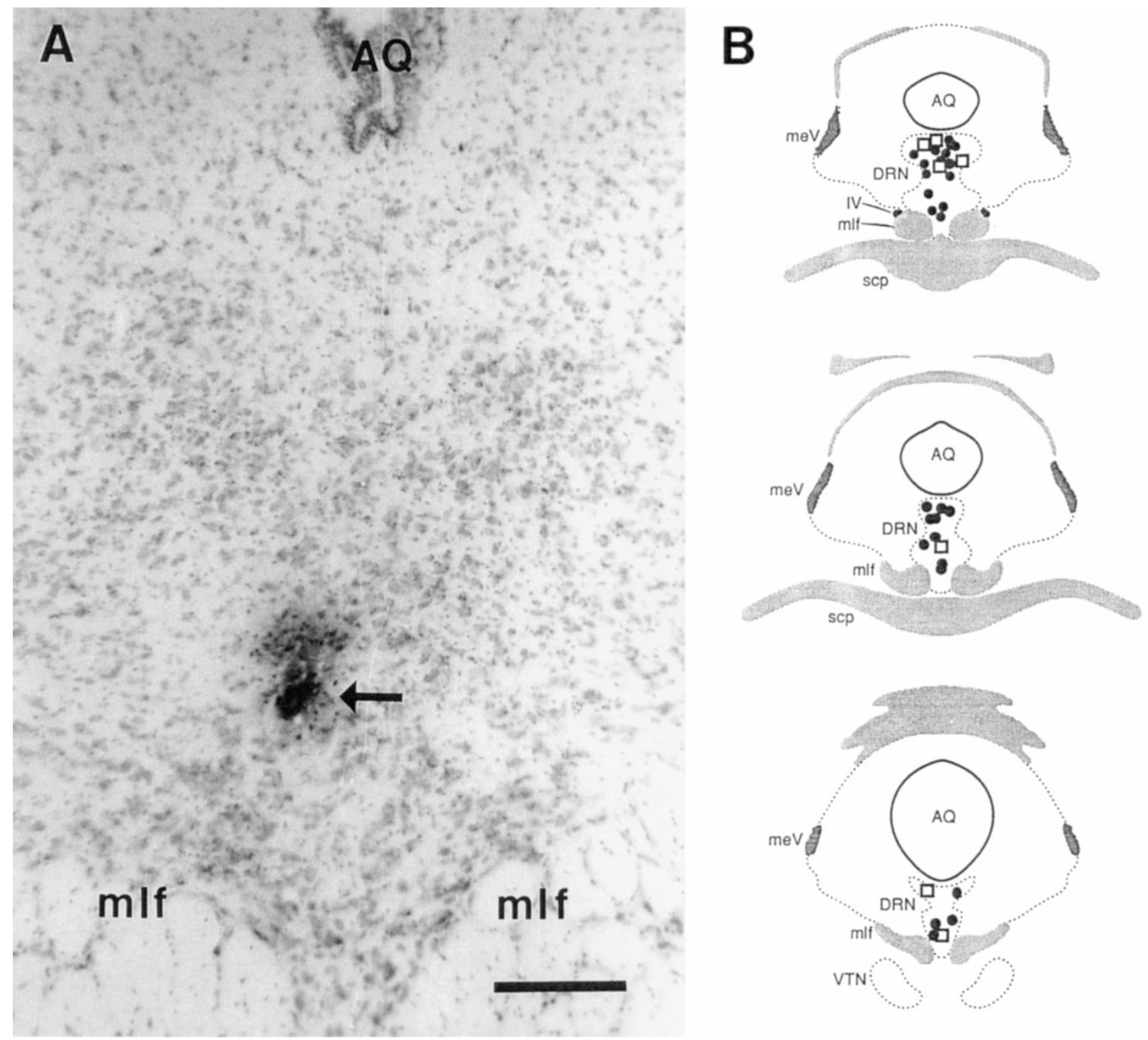

Figure 3. Histological localization of recording sites within the dorsal raphe nucleus. A) Brightfield photomicrograph of a coronal section at the level of the dorsal raphe nucleus. The section is lightly stained with neutral red. The arrow points to the PSB spot in the central part of the nucleus that was created by iontophoresis from the recording pipette. Aq= cerebral aqueduct, $\mathrm{mlf}=$ medial longitudinal fasciculus. The calibration bar represents $50 \mu \mathrm{m}$. B) shown are three levels of the dorsal raphe nucleus, rostral to caudal (top to bottom). Closed circles are recording sites at which CRF (administered either i.c.v. or locally) inhibited neuronal activity and open squares are sites at which CRF increased neuronal discharge. There did not appear to be any topographical organization of qualitatively different responses to CRF.

onstrated increases in extracellular 5-HIAA (Lavicky and Dunn 1993) or hippocampal 5-HT (Reul and Linthorst 1997) after CRF administration. The predominantly inhibitory actions of i.c.v. and intraraphe CRF on dorsal raphe discharge suggest that CRF acts within the cell body region to inhibit neuronal activity, and that this is translated to decreases in terminal 5-HT release. The elevation of extracellular 5-HT produced by relatively high doses of CRF could be the result of actions within the terminal region. For example, high doses of
CRF may increase release through a direct effect on terminals. However, this is considered unlikely given the lack of CRF terminals or receptors in the striatum (Chalmers et al. 1995; Sakanaka et al. 1987; Swanson et al. 1983). Alternatively, CRF could alter activity of striatal afferents that subsequently regulate 5 -HT terminal release via presynaptic heteroreceptors. In this regard the substantia nigra, the source of the dopaminergic innervation of the striatum, is innervated by CRF-immunoreactive fibers (Sakanaka et al. 1987; Swanson et al. 1983). 
Another explanation for the increase in extracellular 5-HT produced by $3.0 \mu \mathrm{g}$ CRF is that it is due to the behavioral activation associated with this dose. Indeed, a previous study suggested that forebrain 5-HT levels were directly correlated to behavioral arousal (Rueter and Jacobs 1996). Consistent with this, the dose of CRF that increased extracellular 5-HT in the present study, was also associated with behavioral activation as indicated by intense grooming, burying, and head shaking. However, lower doses of CRF, comparable to those that decreased extracellular 5-HT in the present study, also produced behavioral activation (Ehlers et al. 1986). Therefore, although enhancement of 5-HT release by 3.0 $\mu \mathrm{g}$ CRF could be attributed to a generalized behavioral activation, behavioral state cannot account for the inhibitory effects of lower doses of CRF on 5-HT levels. A similar dissociation between behavioral state and extracellular 5-HT has been reported after immunological challenge (Linthorst et al. 1995). Different stressors have also been reported to produce varying effects on extracellular 5-HT in various brain regions (Kirby et al. 1997). These results argue against the possibility that forebrain 5-HT levels are solely determined by the state of behavioral activation.

The present neurochemical and electrophysiological results, taken with anatomical findings of CRF fibers and receptors in the dorsal raphe nucleus (Chalmers et al. 1995; Sakanaka et al. 1987; Swanson et al. 1983) support the hypothesis that CRF may serve as a neurotransmitter there to regulate forebrain 5-HT function, analogous to its hypothesized role in the noradrenergic nucleus locus coeruleus (Valentino et al. 1993). Certain manipulations that have been demonstrated to both decrease extracellular 5-HT in forebrain regions and elicit CRF release lead us to predict conditions that would engage CRF neurotransmission in the dorsal raphe nucleus. These conditions include insulin administration (Orosco and Nicolaidis 1994; Plotsky 1985) and acute withdrawal from ethanol (Menzaghi et al. 1994; Weiss et al. 1996) or cocaine (Parsons et al. 1995; Sarnyai et al. 1995). We recently reported that forced swim stress, which induces behavioral depression that is sensitive to antidepressant agents, also decreases extracellular 5-HT measured by in vivo microdialysis in the dorsal raphe nucleus, lateral septum, and amygdala (Chou et al. 1995; Kirby et al. 1995). It is tempting to speculate that some of these conditions elicit CRF release in the dorsal raphe nucleus to subsequently inhibit this serotonergic system. Taken with evidence for CRF hypersecretion in depression (Banki et al. 1987; Gold et al. 1984; Nemeroff et al. 1984, 1988; Roy et al. 1987) and release of CRF during acute drug withdrawal states (Menzaghi et al. 1994; Sarnyai et al. 1995), these findings lead to the intriguing hypothesis that CRF-5-HT interactions play a role in the psychopathology of several disorders, including depression and substance abuse.

\section{ACKNOWLEDGMENTS}

This work was supported by a Research Scientist Development Award MH00840 to R.J.V. and USPHS Grants MH 14654, MH 36262, MH 40008 and MH 42796. The authors wish to thank Dr. Jean Rivier for the generous gift of CRF and Ms. Wei Ping Pu for expert technical assistance.

\section{REFERENCES}

Aghajanian GK, Foote WE, Sheard MH (1968): Lysergic acid diethyl amide: Sensitive neuronal units in the midbrain raphe. Science 161:706-708

Aghajanian GK, Foote WE, Sheard MH (1970): Action of psychotogenic drugs on single midbrain raphe neurons. J Pharmacol Exp Ther 171:178-187

Akaoka H, Saunier C-F, Chergui K, Charlety P, Buda M, Chouvet G (1992): Combining in vivo volume-controlled pressure microejection with extracellular unit recording. J Neurosci Meth 42:119-128

Azmitia EC, Segal M (1978): An autoradiographic analysis of the differential ascending projections of the dorsal and median raphe nuclei in the rat. J Comp Neurol 179:641668

Banki CM, Bissette G, Arato M, O'Connor L and Nemeroff CB (1987): CSF corticotropin-releasing factor-like immunoreactivity in depression and schizophrenia. Am J Psych 144:873-877

Chalmers DT, Lovenberg TW, De Souza EB (1995): Localization of novel corticotropin-releasing factor receptor (CRF2) mRNA expression to specific subcortical nuclei in rat brain: Comparison with CRF1 receptor mRNA expression. J Neurosci 15:6340-6350

Chaouloff F (1993): Physiopharmacological interactions between stress hormones and central serotonergic systems. Brain Res Rev 18:1-32

Chou JM, Kirby LG, Lucki I (1995): Effect of forced swimming stress on extracellular levels of 5-HT in the dorsal raphe nucleus of the rat. Soc Neurosci Abstr 21:2058

De Souza EB (1987): Corticotropin-releasing factor receptors in the rat central nervous system: Characterization and regional distribution. J Neurosci 7:88-100

De Souza EB, Van Loon GR (1986): Brain serotonin and catecholamine responses to repeated stress in rats. Brain Res 367:77-86

Dunn AJ (1988): Stress-related changes in cerebral catecholamine and indoleamine metabolism: lack of effect of adrenalectomy and corticosterone. J Neurochem 51:406412

Dunn AJ, Berridge CW (1987): Corticotropin-releasing factor administration elicits a stress-like activation of cerebral catecholaminergic systems. Pharmacol Biochem Behav 27:685-691

Dunn AJ, Berridge CW (1990): Physiological and behavioral responses to corticotropin-releasing factor administration: Is CRF a mediator of anxiety or stress. Brain Res Rev 15:71-100

Ehlers CL, Reed TK, Henricksen SJ (1986): Effects of corticotropin-releasing factor and growth hormone-releasing 
factor on sleep and activity in rats. Neuroendocrinology 42:467-474

Geyer MA, Puerto A, Dawsey WJ, Knapp S, Bullard WP and Mandell AJ (1976): Histologic and enzymatic studies of the mesolimbic and neostriatal serotonergic pathways. Brian Res 106:257-270

Gold PW, Chrousos GP, Kellner CH (1984): Overview; Psychiatric implications of basic and clinical studies with corticotropin-releasing factor. Am J Psych 141:619-627

Kellar KJ, Brown PA, Madrid J, Bernstein M, VernikosDanellis J, Mehler WR (1977): Origins of serotonin innervation of forebrain structures. Exp Neurol 56:52-62

Kirby LG, Allen AR, Lucki I (1995): Regional differences in the effects of forced swimming on extracellular levels of 5-hydroxytryptamine and 5-hydroxyindoleacetic acid. Brain Res 682:189-196

Kirby LG, Chou-Green JM, Davis K, Lucki I (1997): The effects of different stressors on extracellular 5-hydroxytryptamine and 5-hydroxyindoleacetic acid. Brian Res 760:218-230

Kirby LG, Lucki I (1997): Interaction between the forced swimming test and fluoxetine treatment on extracellular 5-HT and 5-HIAA in the rat. J Pharmacol Exp Ther 282:967-976

Kreiss DS, Wieland S, Lucki I (1993): The presence of a serotonin uptake inhibitor alters pharmacological manipulations of serotonin release. Neuroscience 52:295-301

Lavicky J, Dunn AJ (1993): Corticotropin-releasing factor stimulates catecholamine release in hypothalamus and prefrontal cortex in freely moving rats as assessed by microdialysis. J Neurochem 60:602-612

Liang KC, Melia KR, Miserendino MJD, Falls WA, Campeau S, Davis M (1992): Corticotropin-releasing factor: Longlasting facilitation of the acoustic startle reflex. J Neurosci 12:2303-2312

Linthorst ACE, Flachskamm C, Hopkins SJ, Hoadley ME, Labeur MS, Holsboer F, Reul JMHM (1997): Long-term intracerebroventricular infusion of corticotropin-releasing hormone alters neuroendocrine, neurochemical, autonomic, behavioral, and cytokine responses to the systemic inflammatory challenge. J Neurosci 17:4448-4460

Linthorst ACE, Flachskamm C. Muller-Preuss P, Holsboer F, Reul JMHM (1995): Effect of bacterial endotoxin and interleukin-1b on hippocampal serotonergic neurotransmission, behavioral activity, and free corticosterone levels: an in vivo microdialysis study. J. Neurosci 15:29202934

Menzaghi F, Rassnick S, Heinrichs S, Baldwin H, Pich EM, Weiss F, Koob GF (1994): The role of corticotropinreleasing factor in the anxiogenic effects of ethanol withdrawal. Ann NY Acad Sci 739:176-184

Morgan WW, Rudeen PK, Pfeil KA (1975): Effect of immobilization stress on serotonin content and turnover in regions of the rat brain. Life Sci 17:143-150

Nemeroff C, Widerlov E, Bissette GT, Walleus H, Karlson I, Eklund K, Kilts C, Loosen P, Vale W (1984): Elevated concentrations of CSF corticotropin-releasing factor-like immunoreactivity in depressed patients. Science 226: $1342-1344$

Nemeroff CB, Owens MJ, Bissette GT, Andorn AC, Stanley M (1988): Reduced corticotropin-releasing factor (CRF) binding sites in frontal cortex of suicide patients. Arch Gen Psych 45:577-579

Orosco M, Nicolaidis S (1994): Insulin and glucose-induced changes in feeding and medial hypothalamic monoamines revealed by microdialysis in rats. Brian Res Bull 33:289-297

Owens MJ, Nemeroff CB (1991): Physiology and pharmacology of corticotropin-releasing factor. Pharmacol Rev 43:425-474

Parsons LH, Koob GF, Weiss F (1995): Serotonin dysfunction in the nucleus accumbens of rats during withdrawal after unlimited access to intravenous cocaine. J Pharmacol Exp Ther 274:1182-1191

Plotsky PM (1985): Hypophysiotropic regulation of adenohypophyseal adrenocorticotropin secretion. Fed Proc 344:207-214

Pol O, Campmany L, Gil M, Armario A (1992): Behavioral and neurochemical changes in response to acute stressors: Influence of previous chronic exposure to immobilization. Pharmacol Biochem Behav 42:407-412

Potter E, Sutton S, Donaldson C, Chen R, Perrin M, Lewis K, Sawchenko PE, Vale W (1994): Distribution of corticotropin-releasing factor receptor mRNA expression in the rat brain and pituitary. Proc Natl Acad Sci USA 91:8777-8781

Reul JMHM, Linthorst ACE (1997): Central administration of corticotropin-releasing hormone profoundly stimulates rat hippocampal serotonergic neurotransmission and behavioral activity: No effect of adrenalectomy. Soc Neurosci Abstr 23:119

Roy A, Pickar D, Linnoila M, Chrousos GP, Gold PW (1987): Cerebrospinal fluid corticotropin-releasing hormone in depression: Relationship to noradrenergic function. Psych Res 20:229-237

Rueter LE, Jacobs BL (1996): A microdialysis examination of serotonin release in the rat forebrain induced by behavioral/environmental manipulations. Brain Res 739:57-69

Sakanaka M, Shibasaki T, Lederes K (1987): Corticotropinreleasing factor-like immunoreactivity in the rat brain as revealed by a modified cobalt-glucose oxidediaminobenzidene method. J Comp Neurol 260:256-298

Sarnyai Z, Biro E, Gardi J, Vecsernyes M, Julesz J, Telegdy G (1995): Brain corticotropin-releasing factor mediates 'anxiety-like' behavior induced by cocaine withdrawal in rats. Brain Res 675:89-97

Singh VB, Hao-Phan T, Corley KC, Boadle-Biber MC (1991): Increase in cortical and midbrain tryptophan hydroxylase activity by intracerebroventricular administration of corticotropin-releasing factor: Block by adrenalectomy, by RU 38486 and by bilateral lesions to the central nucleus of the amygdala. Neurochem Int 20:81-92

Swanson LW (1992): Brain Maps Structure of the Rat Brain. Amsterdam, Elsevier

Swanson LW, Sawchenko PE, Rivier J, Vale W (1983): Organization of ovine corticotropin-releasing factor immunoreactive cells and fibers in rat brain: An immunohistochemical study. Neuroendocrinology 36:165-186

Tanaka M, Kohno Y, Nakagawa R, Nishikawa T, Tsuda A, Nagasaki N (1983): Immobilization stress increases serotonin turnover in the extended brain regions in the rat. Kurume Med J 30:35-43 
Vale W, Spiess J, Rivier C, and Rivier J (1981): Characterization of a 41-residue ovine hypothalamic peptide that stimulates secretion of corticotropin and beta-endorphin. Science 213:1394-1397

Valentino RJ, Foote SL, Page ME (1993): The locus coeruleus as a site for integrating corticotropin-releasing factor and noradrenergic mediation of stress responses. Ann NY Acad Sci 697:173-188

Van Loon GR, Shum A, Ho D (1982): Lack of effect of corticotropin-releasing factor on hypothalamic dopamine and serotonin synthesis turnover rates in rats. Peptides 3:799-803

Vertes RP (1991): A PHA-L analysis of ascending projections of the dorsal raphe nucleus in the rat. J Comp Neurol 313:643-668

Weiss F, Parsons LH, Schulteis G, Hyytia P, Lorang MT, Bloom FE, Koob GF (1996): Ethanol self-administration restores withdrawal-associated deficiencies in accumbal dopamine and 5-hydroxytryptamine release in dependent rats. J Neurosci 16:3474-3485 